\title{
Fabrication of High Aspect Ratio Microcoils for Electromagnetic Actuators
}

\author{
Daiji Noda, Masaru Setomoto and Tadashi Hattori \\ Laboratory of Advanced Science and Technology for Industry, University of Hyogo \\ etpan
}

\section{Introduction}

Actuators are finding increasing use in the various fields and many applications. Therefore, it is one of the most important components in various machines because its performance determines to operate a machine. Among the actuators, we are focusing on electromagnetic actuators that could be driven at a low voltage, high power, high efficiency, and low cost. Then, the majority of actuators used in macroscopic applications are in this type. Recently, the size reduction and sophistication are required for parts and devices. Therefore, actuators, which hold big volume and weight with a part of a product, have been required to reduce their size. Nonetheless, electromagnetic actuators are known to be unsuitable for miniaturization because the allowable current carrying capacity is very small when current paths of coil are microscopic, making it difficult to obtain high power. In addition, it is very difficult to process microscopic current paths by mean of conventional machining technology. Therefore, the key technology to realizing practical electromagnetic microactuators is micro-fabrication process.

On the other hand, LIGA (German acronym for Lithographite, Galvanoformung, and Abformung) process (Becker et al. 1986) could be used to fabricate nano- and micro-parts for devices. The LIGA is a total process and have three major steps in the process including $\mathrm{X}$ ray lithography, electroforming to fabricate metallic molds, and the use of these molds to form required parts of plastic micro structure. The X-rays that are generated by synchrotron radiation have high directivity and transmission characteristics, and could be used to expose photoresist to deep depths of $1 \mathrm{~mm}$ or more. In this X-ray lithography, the NewSUBARU synchrotron radiation facility at our university (Ando et al. 1998) was used. This was operated at energy of 1.0 or $1.5 \mathrm{GeV}$ modes. The X-ray exposure at beamline 11 (BL11) of NewSUBARU was carried out with the workpiece held in a specially manufactured nine parts operation exposure stage (Mekaru et al. 2001), in which two axes are moved by piezoelectric elements, while five of other axes are moved using stepping motor; the remaining two axes are rotated by stepping motor. Thus, this X-ray exposure stage could make it feasible to create three-dimensional (3D) structures (Mekaru et al. 2002).

In this research, we have achieved development of 3D deep X-ray lithography technique that we used to produce a high aspect ratio spiral microcoil patterns (Mochizuki et al. 2007; Matsumoto et al. 2008; Setomoto et al. 2008; Noda et al. 2007, and Noda et al. 2008a). With this technique, it is very expected to fabricate high aspect ratio of coil line structures with

Source: Micro Electronic and Mechanical Systems, Book edited by: Kenichi Takahata, ISBN 978-953-307-027-8, pp. 572, December 2009, INTECH, Croatia, downloaded from SCIYO.COM 
narrow line widths. This electromagnetic actuator, which features high aspect ratio coil, would also be possible to provide enhanced high suction force in spite of miniature size.

\section{Design and simulation of electromagnetic actuator}

An electromagnetic type actuator incorporating a magnetic circuit was designed. As the design of magnetic circuit, we have used the type called "open frame solenoid", which is open on the sides (Matsumoto et al. 2008) as shown in Fig. 1. The material of magnetic core (fixed core and plunger) and shield parts (yoke) were used a Permalloy 45, which is a nickel iron alloys, because it has the largest permeability among soft magnetic metals. When a voltage is applied to the coil lines, a magnetic flux forms in a gap, which is deforming a magnetic field and producing suction force on a plunger.

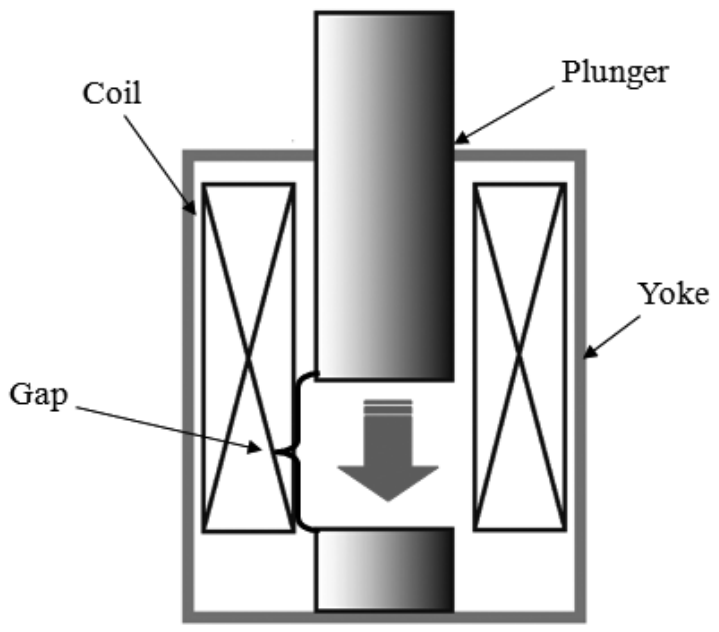

Fig. 1. Designed model of actuator operation with magnetic circuit.

An acrylic pipe with an outside diameter of $5 \mathrm{~mm}$ was used as a base material for coil. This material is PMMA (polymethlymethacrylate) which exhibits a positive type photoresist. Therefore, it could directly be exposed to X-ray lithography to form high aspect ratio coil line structures on pipe surface. Figure 2 shows the image diagrams of coil lines on pipe surface. Wire type coil is limited to copper wire size. However, high aspect ratio type in this research is fabricated using X-ray lithography technique. Therefore, coil line width was obtained narrow and deep depth, that is high aspect ratio lines were formed.

First, we have simulated suction force in high aspect ratio coil line structure. In this model, a magneto-motive force is proportional to squares of current path. If the aspect ratio of coil liens is increased, cross sectional area of coil lines is also increased allowing a greater current path. Figure 3 shows results of suction force and permit current path in different aspect ratio. Here, we used coil parameters as coil line width of $10 \mu \mathrm{m}$ and coil turns of 675 . And, the gap between plunger and fixed core was decided to $1 \mathrm{~mm}$ length. When an aspect ratio is reached 5, suction force may be about 25 times as large as aspect ratio of 1 . These calculated results indicated that suction force could be increased using high aspect ratio coil line structure. 

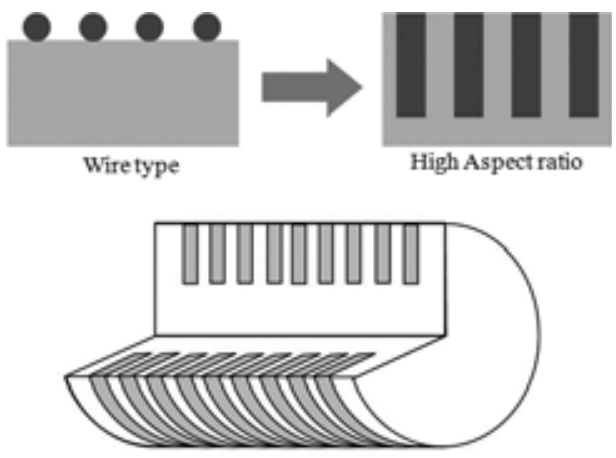

Fig. 2. Image diagram of high aspect ratio coil lines.

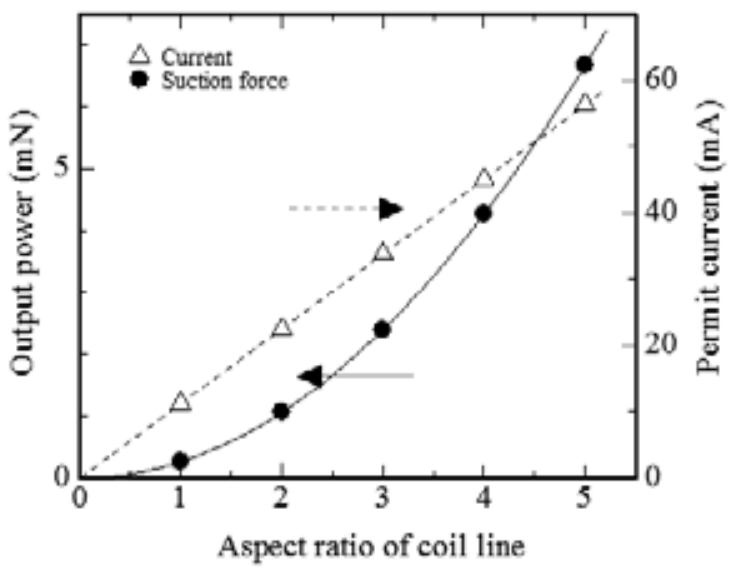

Fig. 3. Calculation of suction force and permit current in different aspect ratio.

In order to estimate of simulation results, we have also fabricated a measurement system in order to measure a suction force of designed electromagnetic actuator, as shown in Fig. 4. The measurement system was provided with a movable target, which moved with plunger. The target was suspended by means of coil spring. To determine suction force, we have measured the displacement of the target using laser displacement meter. Thus, suction force could be determined by the displacement data and spring constant of used coil spring. The gap adjustment was performed by combining a coarse-motion XY stage and fine-motion XY stage. We measured suction force generated by actuator using this measurement system. Coil is used acrylic pipe as base coil part and winding of polyurethane coated copper wire having $50 \mu \mathrm{m}$ in wire diameter. Figure 5 shows that the theoretical values by calculation and actual measurement values of suction force were compared. The measurement results were relatively in good agreement with the theoretical values. One problem of assumed magnetic path was that magnetic flux could be extremely different from the reality in small gap region. The measurement results indicate the tendency in good agreement. Therefore, this measurement system was reliable. 


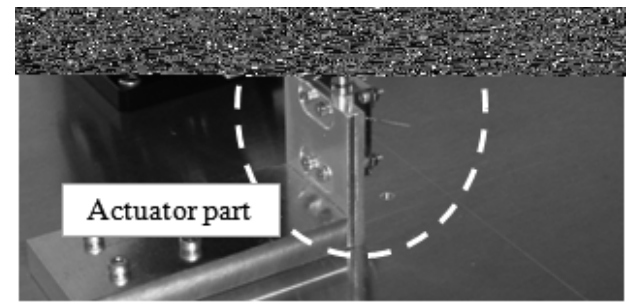

Fig. 4. Measurement system of suction force fro electromagnetic actuator.

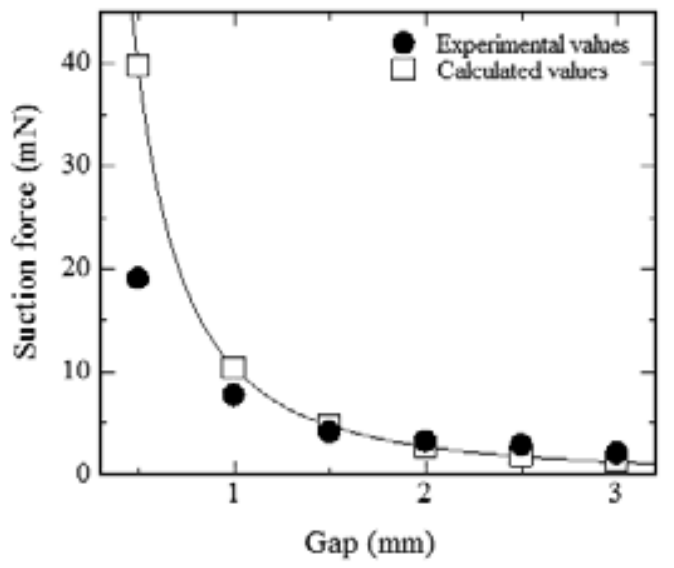

Fig. 5. Suction force comparison between measurement values and calculation values.

\section{Fabrication process for coil lines}

A spiral coil lines was formed on surface of acrylic pipe using X-ray lithography and metallization techniques. Fabrication processes for coil lines were shown in Fig. 6. First, a spiral coil structure of photoresist was formed on pipe surface using deep X-ray lithography. Next, copper was thinly deposited on coil line structures by sputtering to use as an electrode for electroforming. Then, the acrylic pipe was immersed into a copper plating bath for electroforming. Finally, the plated copper was dissolved on form coil lines 
by leaving only deposit in the spiral structure using chemical copper etching. The following sections were discussed detailed descriptions of each process.
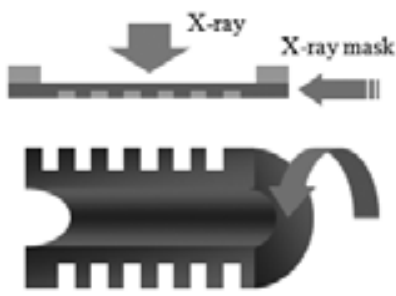

I. X-ray lithography

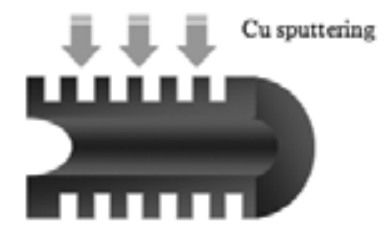

II. Formation of seed layer

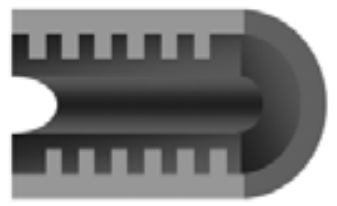

III. Electroforming of copper

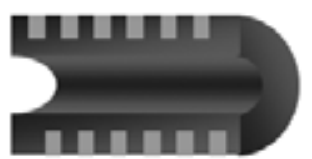

IV. Chemical etching

Fig. 6. Fabrication process of coil lines.

\subsection{X-ray Lithography}

We have mainly used X-ray mask having two line width patterns with 10 and $30 \mu \mathrm{m}$, respectively. Therefore, a spiral structure of coil lines was obtained 10 or $30 \mu \mathrm{m}$ line width. To fabricate spiral micro coil lines, acrylic pipe was rotated using stepping motor and movement of X-ray mask was controlled by piezoelectric element. The X-ray exposure chamber was provided to perform 3D X-ray lithography, as shown in Fig. 7. In this study,

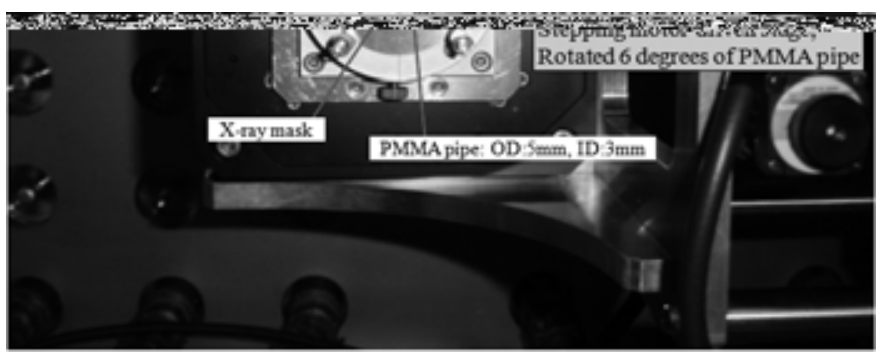

Fig. 7. Picture of multi operation X-ray exposure stage. 
exposure process was divided into 60 steps in order to closely to continuity exposure. Thus, the pipe was rotated through an angle of 6 degrees while the X-ray mask was advanced by just 1/ 60 pitch of line pattern for each X-ray exposure cycles, as shown in Fig. 8. After X-ray lithography, spiral structure was developed on pipe surface, which was carried out using a GG developer (diethyleneglycolmonobutyether, 60 vol\%; morpholine, 20 vol\%; ethanoaine, 5 vol\% \& distilled water, 15 vol\%) at room temperature. After this development, spiral structure was obtained.

The spiral structure of coil lines was observed using scanning electron microscope (SEM). The processing depth, that was determined aspect ratio of coil lines, could be controlled by the X-ray dose during X-ray exposure and the development time. Figure 9 shows relationship between processing depth and development time with three parameters of $\mathrm{X}$ ray dose. Figure 10 shows the SEM image of spiral structure of coil lines with a pitch of 20 $\mu \mathrm{m}$. In this case, an aspect ratio was achieved about 5 as coil line width of $10 \mu \mathrm{m}$. To use in $30 \mu \mathrm{m}$ lines and space patterns, we obtained an aspect ratio of 2 , as shown in Fig. 11. From these figures, we were able to confirm the joints between each section of spiral pattern were perfectly aligned.

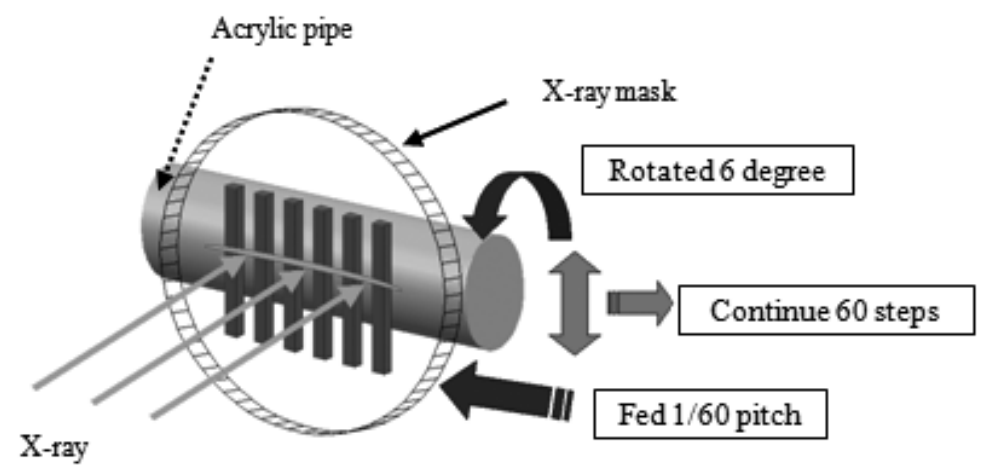

Fig. 8. Image diagram of X-ray lithography for spiral coil.

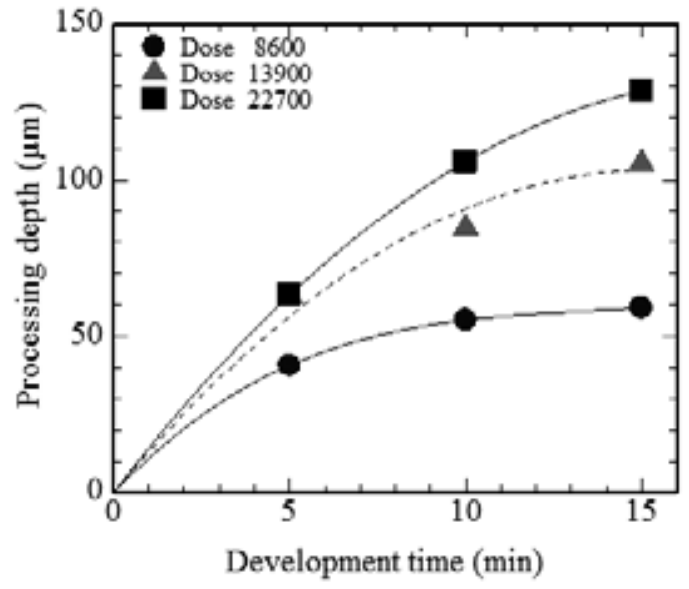

Fig. 9. Relationship between processing depth and development time. 


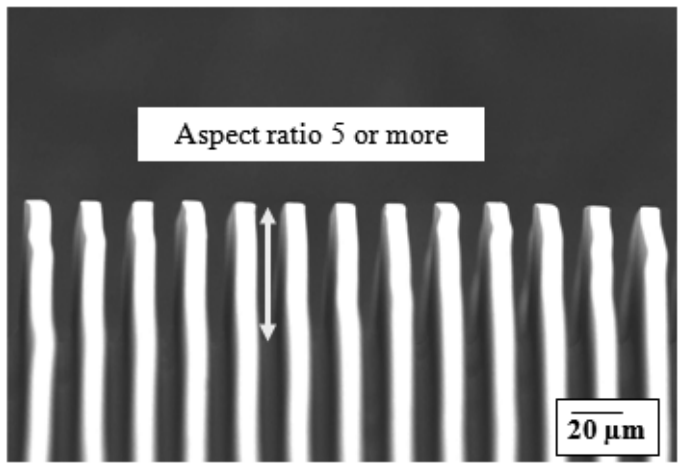

Fig. 10. SEM image of coil line width of $10 \mu \mathrm{m}$.

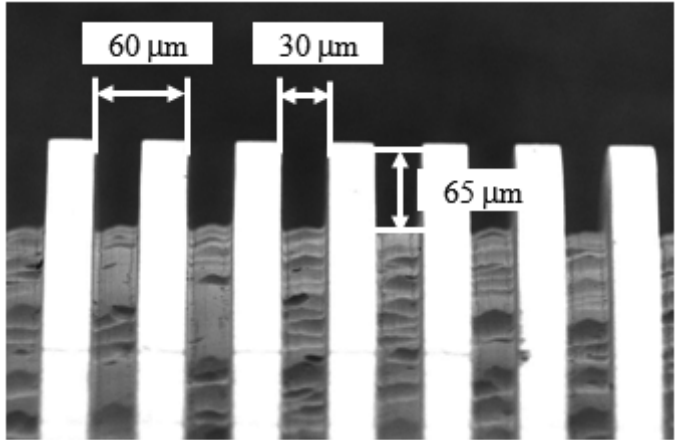

Fig. 11. SEM image of coil line width of $30 \mu \mathrm{m}$.

\subsection{Formation of seed layer}

Since an acrylic pipe is non-conductive material, a conductive seed layer is required for electroforming. We formed a seed layer on pipe surface using sputtering. In order to realize a circumferentially flat seed layer, we have performed sputtering rotating the pipe at $3 \mathrm{rpm}$ and sputtering at three hours. First, it was found that a resistance of seed layer between both ends was very high. To solve this problem, we moved the position of pipe along its axis (Noda et al. 2007). As this result, we successfully produced an approximately $300 \mathrm{~nm}$ thick seed layer, which was level in the circumferential direction of the pip surface.

\subsection{Copper electroforming}

Following a seed layer deposition, we immersed an acrylic pipe in a copper sulphate solution bath including a levelling agent to uniform electroforming. To form plating film growth uniformity over the all coil line patterns, the pipe was connected to mixer and rotated in the plating solution. Figure 12 shows the plating bath.

In first plating, it is not good result to be due to voids that has generated inside the plating film. It was confirmed that these voids were produced inside coil line patterns had prevented the formation of satisfactory coil lines. Since high aspect ratio structure had been formed to be electroplated, it was estimated that air bubbles would remain inside high aspect ratio structure due to surface tension when the pipe was dipped in the plating 


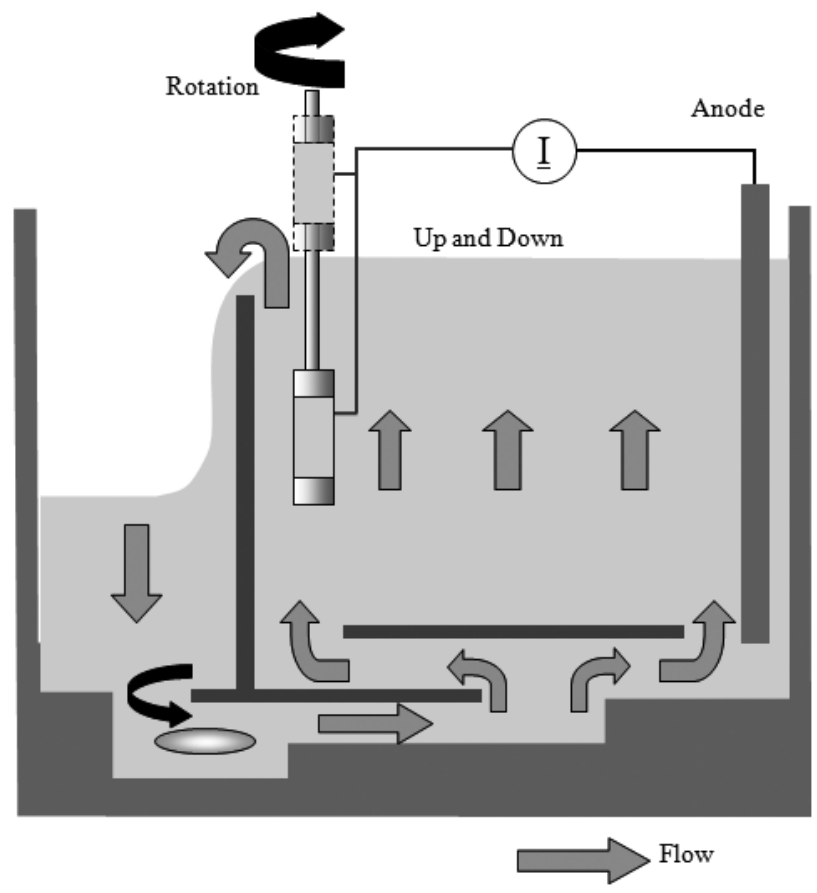

Fig. 12. Image diagram of copper electroforing bath.

solution. By cleaning air bubbles from spiral structures, a vacuum deforming was used before electroforming. In addition, the pipe was lifted out of the bath a few times, circulating the plating liquid in the patterned area during the plating. After these improvements, we confirmed to obtain a void-free copper plating film, as shown in Fig. 13.

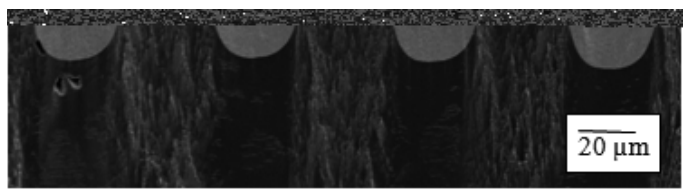

Fig. 13. SEM image of coil line width of $30 \mu \mathrm{m}$ after copper electroforming.

However, for those whose aspect ratio was about 5 , the electroforming did not even enter the grooves in the majority of area. When the aspect ratio of coil lines was higher, this tendency was more significant. 


\subsection{Formation of coil lines}

We were investigating the formation of coil lines using etching and machining, respectively. Figure 14 shows the result by machining. It was very good result and copper coil lines were separated. However, copper and acrylic pipe of spiral structure were removed together by machining. Then, an aspect ratio of coil lines was changed and unknown in this result. On the other hand, isotropic copper etching was performed until the insulated portions of the wiring were exposed. Therefore, it was not changed an aspect ratio of coil lines. For copper etching, E-process-W etchant (made by Meltex co., ltd.) was used. In this etching process, the pipe rotation mechanism was also used to rotate the acrylic pipe in the etchant to ensure uniform pipe surface etching. As a result, we produced the coil lines by etching the copper until the protrusions of spiral structures were exposed, as shown in Fig. 15.

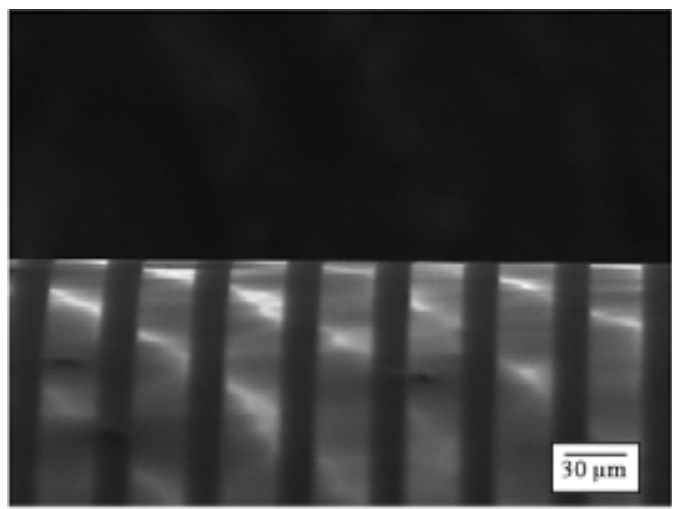

Fig. 14. SEM image of coil lines by machining.

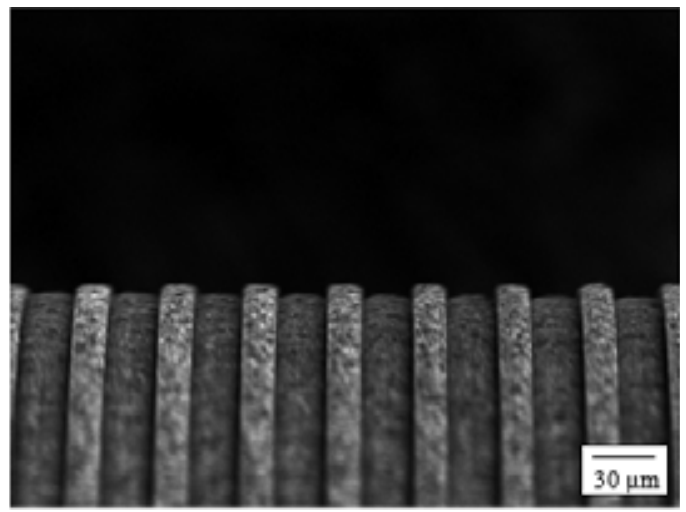

Fig. 15. SEM image of coil lines by chemical etching.

\section{Measurement of suction force}

We have measured the suction force using fabricated spiral coil with narrow and high aspect ratio coil lines. Figure 16 shows the actuator part in measurement system. From this figure, this system is very easy to exchange a coil part. The gap between plunger and fixed 
core was adjusted XY stages. Figure 17 shows that calculated values and actual measurement of suction force in this system were compared. In this case, we used a spiral coil having a width of $30 \mu \mathrm{m}$ and aspect ratio of about 2 . The measurement results were relatively in good agreement with calculation values. Here, result in small gap region was tended to include considerable errors. The reason is same in the result of Fig. 5.

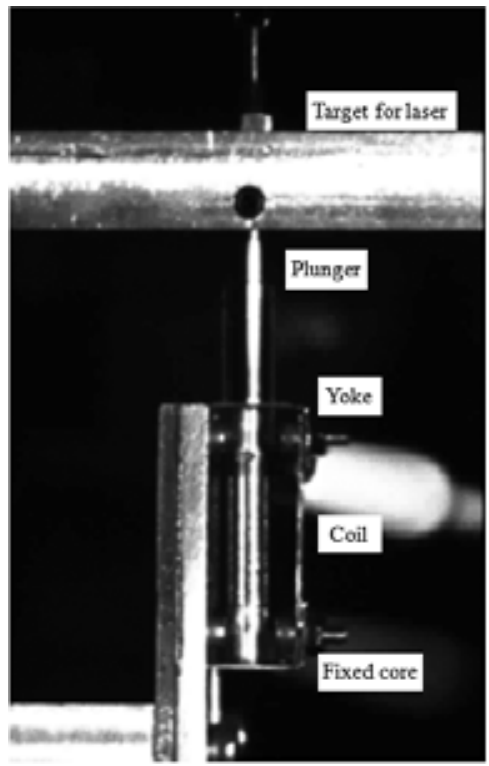

Fig. 16. Picture of actuator part in measurement system.

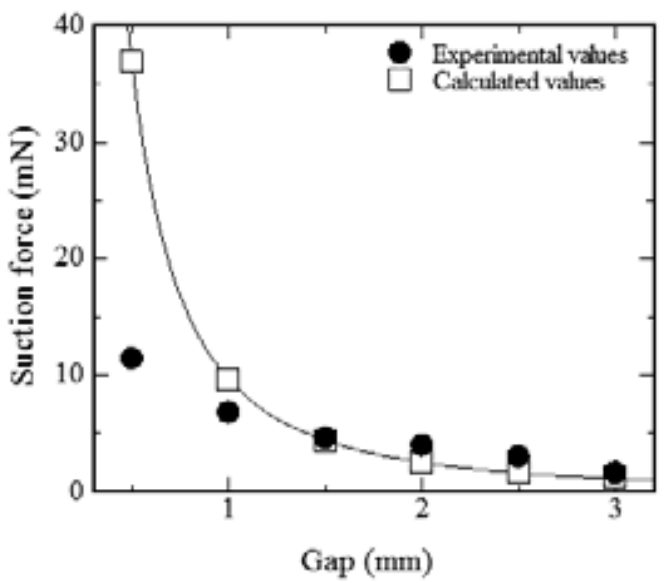

Fig. 17. Suction force comparison between calculattion and measurement values.

Figure 18 shows the suction force different aspect ratio coil lines using the gap of $1.5 \mathrm{~mm}$ in good agreement with calculation values. Increasing an aspect ratio of coil lines generates higher suction force. But, we have only measured under an aspect ratio of 2 . Currently, we 
have been proceedings to measure the suction force by providing the spiral coils with higher aspect ratio coil line structures produced by X-ray lithography and metallization techniques.

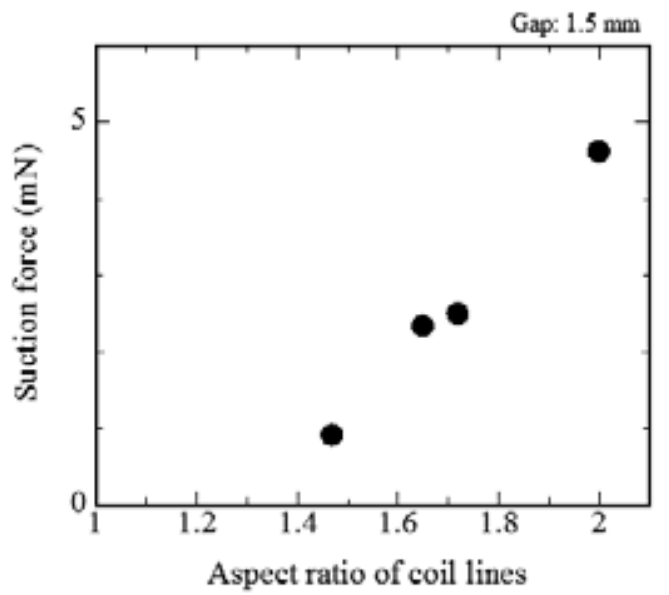

Fig. 18. Suction force different aspect ratio.

\section{Development of microcoil}

Acrylic pipe in outside diameter of $5 \mathrm{~mm}$ has been used in these experiments. Therefore, coil size is too large. Then, we were proposed and new fabrication process and tried to fabricate microcoils. First, we have calculated coil performance with high aspect ratio coil lines. Figure 19 shows calculation results of quality factor ( $Q$ factor) and resistance for different aspect ratio structures (Noda et al. 2008b). Here, we used coil parameters as coil turns of 20 and coil line width of $10 \mu \mathrm{m}$. And, coil diameter is $0.5 \mathrm{~mm}$ and coil length is $0.4 \mathrm{~mm}$. From this figure, $\mathrm{Q}$ factor was very improved increasing the aspect ratio of coil lines. Therefore, it is also very expected that high performance microcoil with high aspect ratio could be obtained.

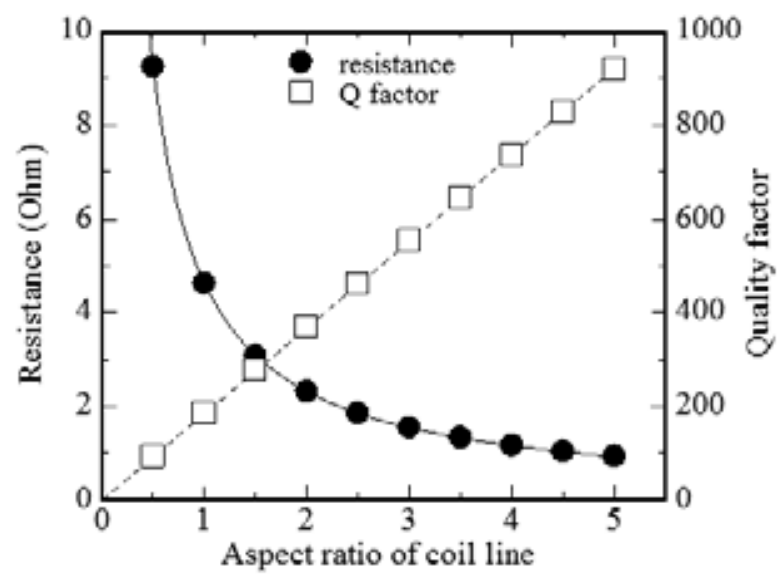

Fig. 19. Calculation of $\mathrm{Q}$ factor and resistance different aspect ratio. 
To obtain microcoil with high aspect ratio coil lines, we used metal bar as coil base material with a diameter of 0.5 to $1 \mathrm{~mm}$. However, metal bar was not directly exposed. Then, we applied a PMMA on a master metal bar using dipping method (Noda et al. 2008b; Yamashita et al. 2006 \& Noda et al. 2008c). The thickness of PMMA was determined as coil line depth. Thus, it is very important factor in microcoil. The process was largely identical to that used for the acrylic pipe expect the final etching step, as shown in Fig. 20.

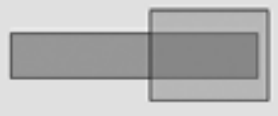

Dipping

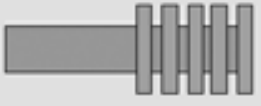

$\mathrm{X}$-ray lithograpky

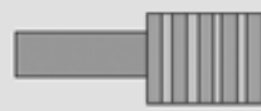

Cu electroforming

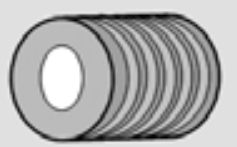

Etching of master bar

Fig. 20. Fabrication process using metal master bar.

\subsection{Dipping method}

We used a dipping method in order to obtain a thick layer of photoresist on metal bar. Figure 21 shows dipping method. This method comprises four steps: dipping, recovery, air drying, and baking. The master bar was dipped in a photoresist solution while rotating the cylinder shaft. Then, it was dried in the air while being rotated before the baking. In recoating, the master bar was pre-baked for short period of time before following the same steps to apply photoresist. Baking was performed in the final step. To prepare a PMMA solution, a PMMA sheet was crushed and dissolved in 2-ethoxyethyl acetate for more than 15 hours (Yamashita et al. 2006). A highly viscous photoresist solution and control over the centrifugal force are important factors to obtain a thick uniform coating, and thus enable the production of high aspect ratio coil line structures (Noda et al. 2008b).

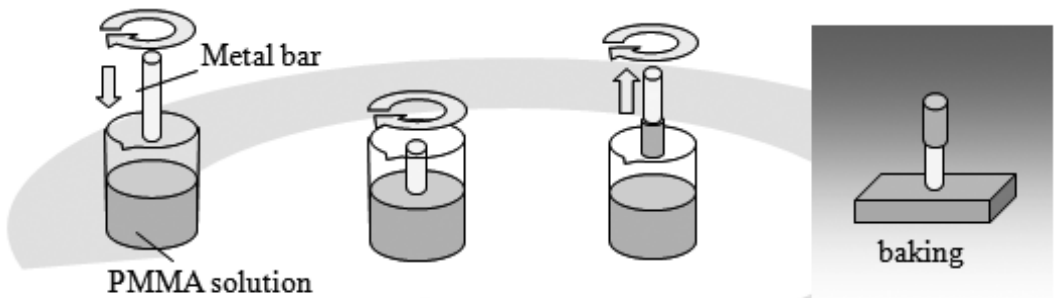

Fig. 21. Image diagram of dipping method.

\subsection{Results and discussions}

We were able to control the thickness of the PMMA on the metal bar by the speed of rotation and concentration of PMMA solution. PMMA thickness of more than $100 \mu \mathrm{m}$ was obtained in a single coating. Thus, the aspect ratio achieved for $30 \mu \mathrm{m}$ width spiral structure was greater than 3 . 
A spiral structure was formed in the PMMA on the metal bar using X-ray lithography technique. In the case, we used an X-ray mask with $30 \mu \mathrm{m}$ width with a mask space ratio of 1:1. The diameter of the metal bar was used at $0.5 \mathrm{~mm}$. Figure 22 shows a SEM image of a spiral structure with a pitch of $60 \mu \mathrm{m}$. This figure shows that the aspect ratio realized was about 6 because the spiral structure widths were narrower than the designed $30 \mu \mathrm{m}$ width. Next, we performed a metallization process, including electroforming and master bar etching. In this case of metal bar, the master bar acts as the seed layer for electroforming. Therefore, the plating metal grew from the surface of the master bar completely filling the

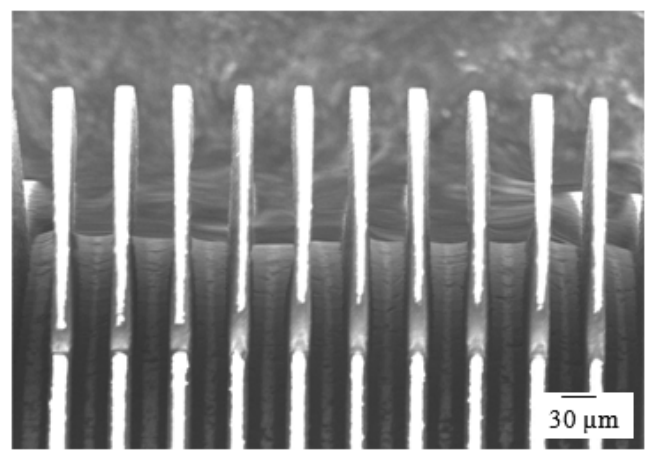

Fig. 22. SEM image of coil lines with high aspect ratio structures.

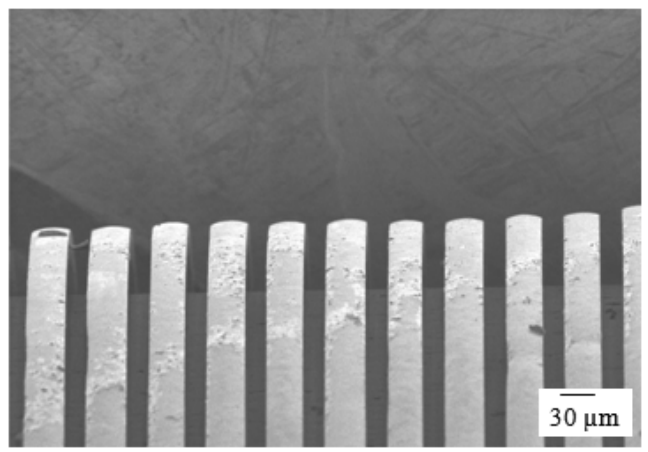

Fig. 23. SEM image of coil lines after photoresist etching.

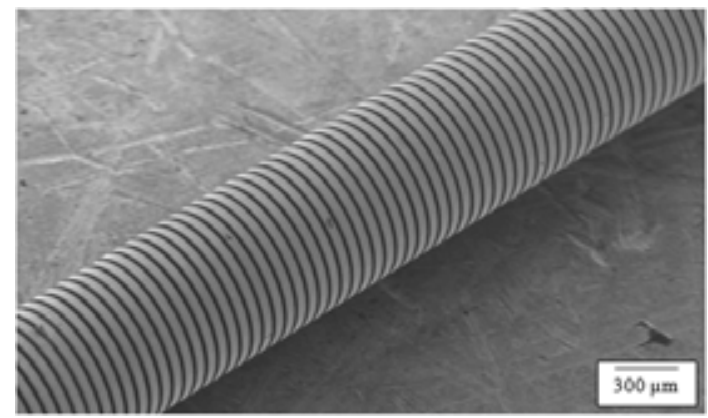

Fig. 24. SEM image of coil lines on the whole. 
high aspect ratio spiral structures. Figure 23 shows a SEM image of coil lines with a pitch of $60 \mu \mathrm{m}$ after removing the spiral photoresist patterns. This aspect ratio was obtained about 2 . Then, we succeeded to fabricate a microcoil having a pitch of $60 \mu \mathrm{m}$ on metal bar of $0.5 \mathrm{~mm}$ in diameter, as shown in Fig. 24.

Figure 25 shows a comparison of the size of the fabricated microcoils. On the right was a coil fabricated using acrylic pipe as the base material, and on the left was a microcoil using metal bar. We were able to fabricate a $0.5 \mathrm{~mm}$ diameter microcoil with high aspect ratio. It is expected to fabricate higher aspect ratio coil lines using metal bar as coil base material.

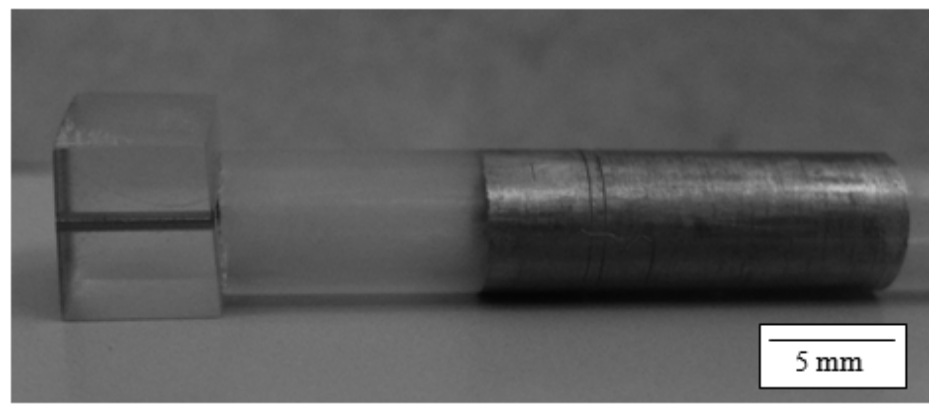

Fig. 25. Picture of fabricated microcoils with $1 \mathrm{~mm}$ diameter and acrylic pipe.

\subsection{Fabrication of microcoil using LIGA process}

In order to produce a spiral microcoil, the LIGA process was modified to the 3D processing method (Mekaru et al. 2004; Mekaru et al. 2005 \& Mekaru et al. 2007). First, Au electroless plated to the surface of a brass rod with diameter of $0.46 \mathrm{~mm}$, and PMMA of $10 \mu \mathrm{m}$ thickness was applied by a dipping method. To fabricate a master of coil line strtuctures, 3D X-ray lithography was performed. In this case, $10 \mu \mathrm{m}$ line width pattern was used for X-ray mask. Figure 26 shows the back view of X-ray exposure chamber at BL 11 used in this experiment. An X-ray exposure process was simplified only two steps (Mekaru et al. 2005), because diameter was very slim comparison with acrylic pipe diameter. Figure 27 shows the PMMA microstructure with a coil line width of $10 \mu \mathrm{m}$ and thickness of $10 \mu \mathrm{m}$, which was spirally produced on the surface of brass rod with diameter of $0.46 \mathrm{~mm}$.

Next, Ni electroforming was carried out to fabricate a metallic mold. Ne electroforming performed in conditions that nickel sulfamate used for electroforming solution. The brass rod and the PMMA microstructure in the inside of the Ni mold were removed by chemical etching. Then, the Ni mold wad completed having spiral structures, as shown in Fig. 28. In order to obtain this cross sectional photograph, one of the metallic mold was sectional. From this pattern, it was confirmed that the form of the master was transferred faithfully. The edge portion of the slot was also observed clearly.

For the replication process, an enscrewing injection machine (made by Juken Machine Works Co., Ltd.) was used to fabricate microcoil. In order to utilize the demolding process, it was necessary to synchronize the speed of rotation and mold opening according to the pitch of worm. Figure 29 shows the concept of worm demolding. Liquid crystal polymer (LCP) was the select as resin material, consideration for enhancing adhesion to form copper electroforming. As the result of injection molding, we succeeded in fabrication of resin core such small size worm, as shown in Fig. 30. Unlike the SEM image of the master of the 


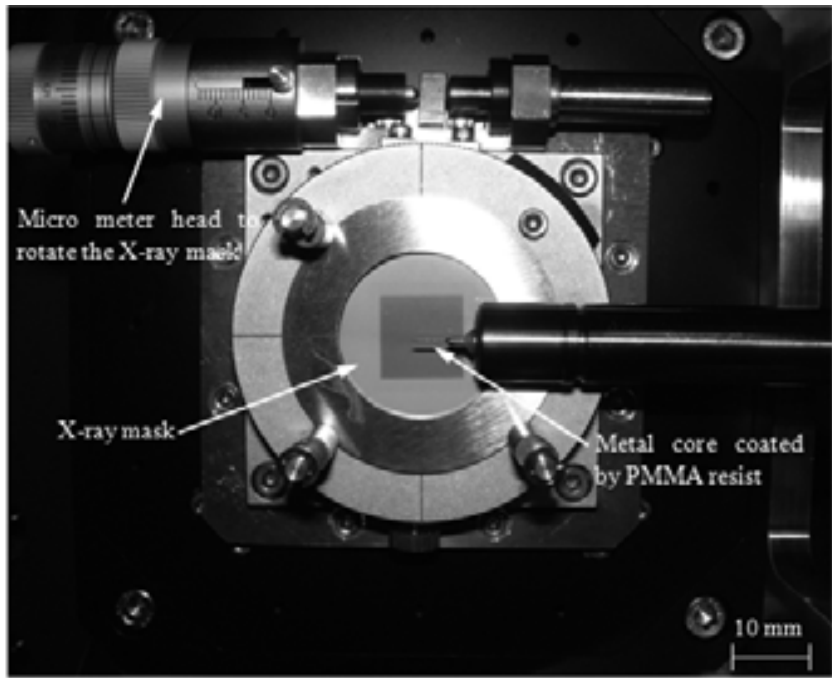

Fig. 26. Picture of back view of X-ray exposure chamber.
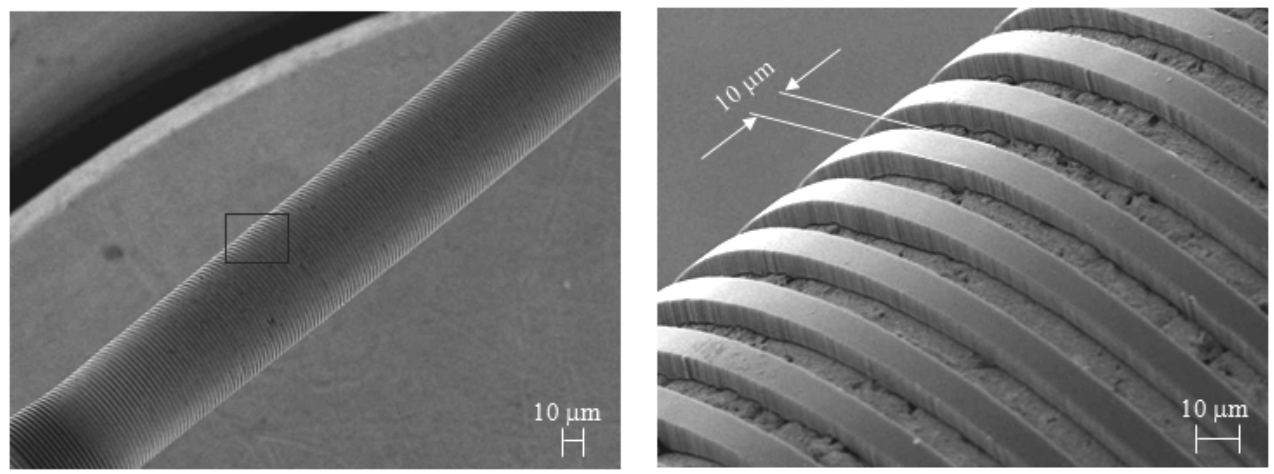

Fig. 27. SEM image of PMMA mold master.
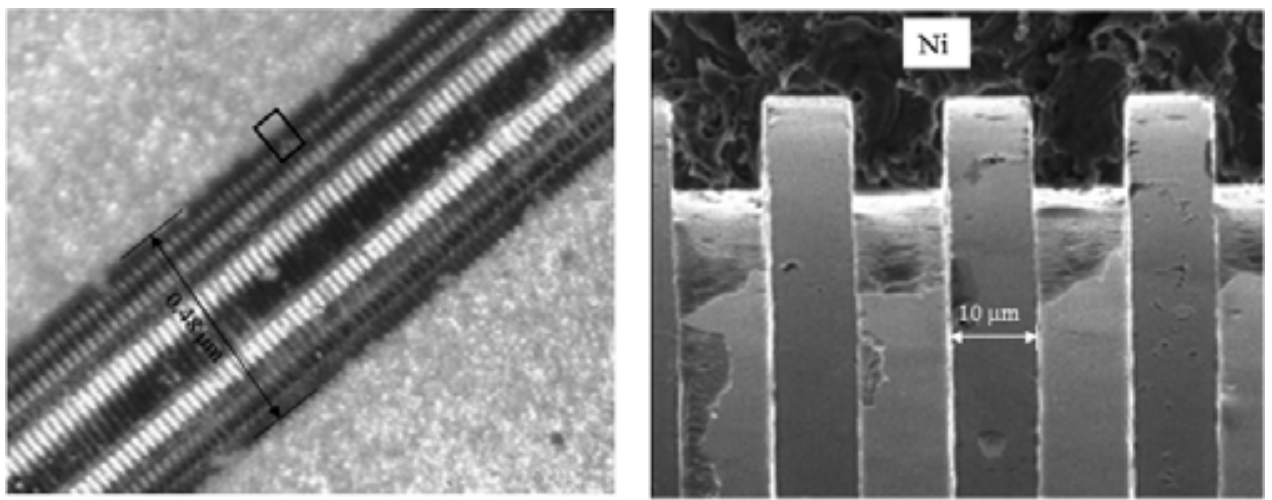

Fig. 28. SEM image of Ni mold. 


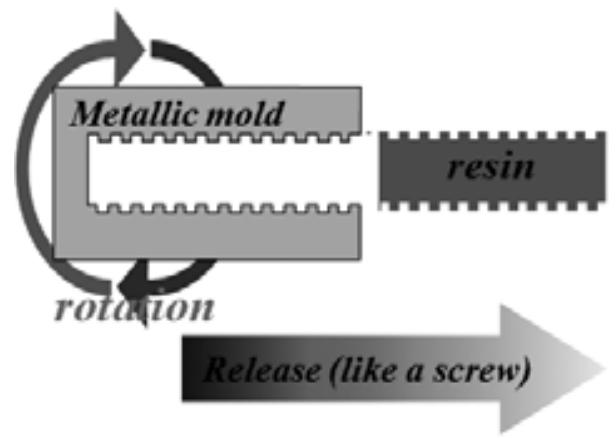

Fig. 29. Conept of worm deolding.
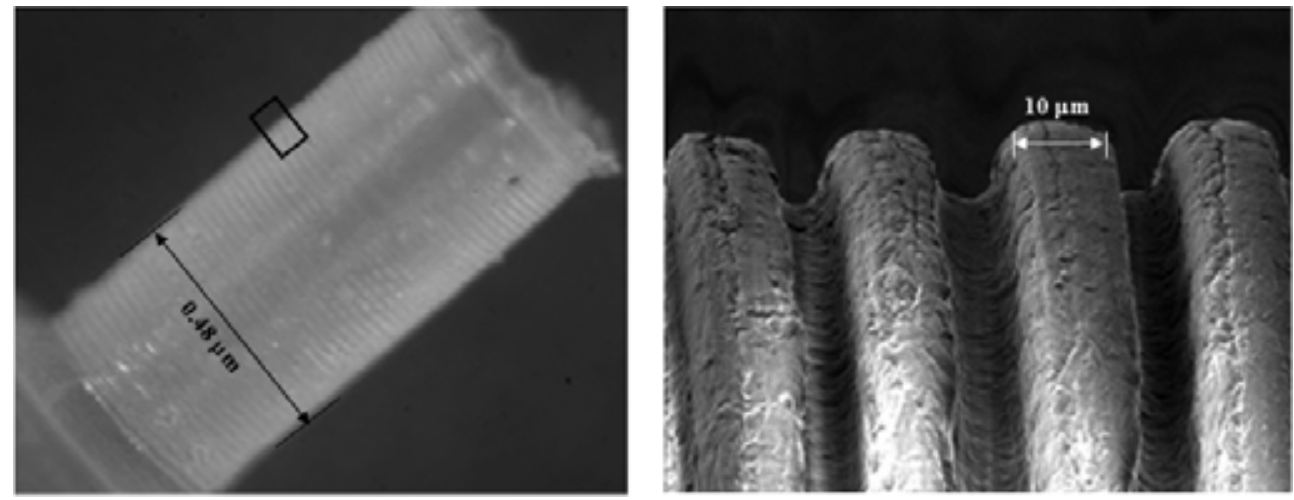

Fig. 30. SEM image of resin core.

metallic mold, and inside of the Ni mold shown in Figs. 27 and 28, the sharpness could not be checked for the edge portion of the microstructure of the spiral form. This might be a gas that evaporated the LCP. Furthermore, the edge portion might have become round by frictional heat during the unscrewing of the demolding process (Mekaru et al. 2005).

All the screw portion of the LCP core was covered by copper electroforming after pretreating and degreasing. Silver paste was applied to the both sides of the microcoil as electrodes, and the coil line part was coated by epoxy resin for insulated protection. Figure 31 shows the completed spiral microcoil with $1 \mathrm{~mm}$ in length, $0.48 \mathrm{~mm}$ in diameter, and 15 turns. The spiral copper coil lines could be seen clearly. This inductance and the $\mathrm{Q}$ factor at $1 \mathrm{GHz}$ were $91 \mathrm{nH}$ and 5.8, respectively (Mekaru et al. 2005). From these results, LIGA process has very advantage to produce high aspect ratio microstructures.

\section{Conclusions}

We have fabricated spiral coil with high aspect ratio coil lines for solenoid type electromagnetic actuator using 3D X-ray lithography and metallization techniques. Using these techniques, we succeeded in producing a spiral structure with $10 \mu \mathrm{m}$ width coil line structures with maximum aspect ratio of about 5 . We also succeeded in electroforming copper in the high aspect ratio structure and forming a coil by isotropic copper etching. Then, we could be obtained coil pattern on acrylic pipe with high aspect ratio. 


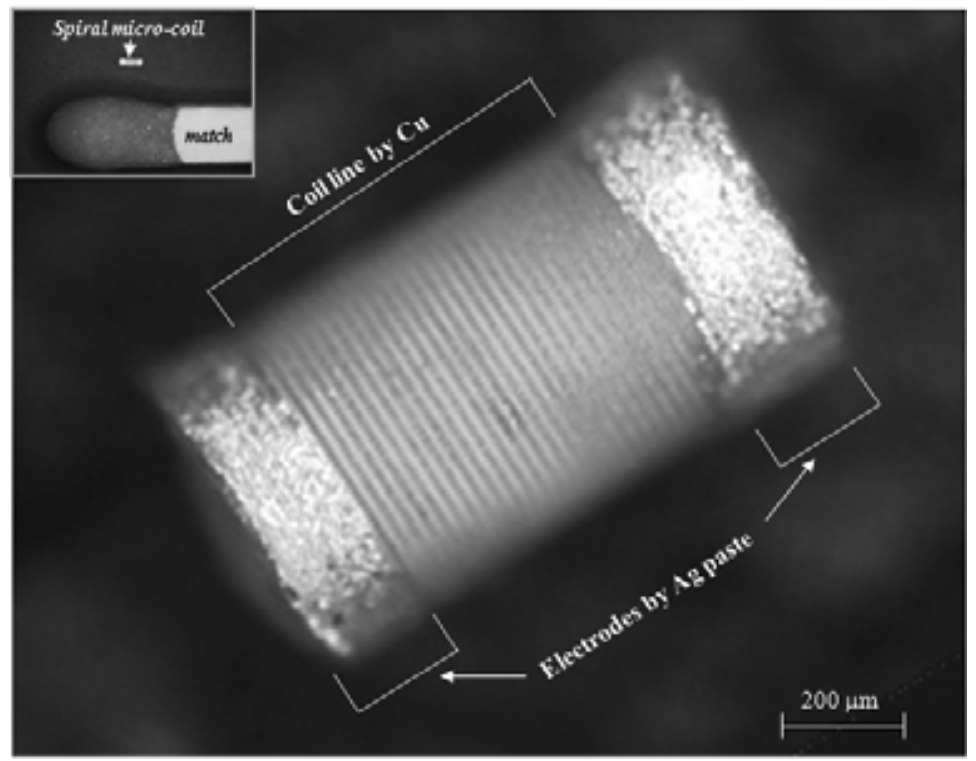

Fig. 31. SEM image of copleted spiral microcoil.

In addition, we produced a measurement system to measure the suction force produced by these electromagnetic actuators. The results of these suction force measurements enabled us to confirm the results of calculation values. The measurement results were in relatively good agreement with the calculated values.

We also attempted to fabricate microcoil with diameters of less than $1 \mathrm{~mm}$. Using a dipping method, photoresist thickness of over $100 \mu \mathrm{m}$ were achieved using highly viscous solution and controlling the centrifugal force. We succeeded in producing a spiral microcoil with 30 $\mu \mathrm{m}$ width with an aspect ratio of about 2 using same fabrication process. And, we achieved development of a method to fabricate the 3D spiral microcoil using LIGA process. The size of the microcoil was $1 \mathrm{~mm}$ in length and $0.48 \mathrm{~mm}$ in diameter.

Using these techniques, we were able to fabricate microcoils with high aspect ratio coil lines. Thus, it is very expected that electromagnetic actuators with high suction force could be manufactured despite their miniature size.

\section{Acknowledgment}

This research was partially supported by the Grant-in-Aid for Scientific Research on Priority Area (No. 438, "Next-Generation Actuators Leading Breakthroughs"), No. 16078212, from the Ministry of Education, Culture, Sports, Science and Technology, dapan. This contract research from the New Industry Research Organization (NIRO) was supported finically by the Ministry of Economy, Trade and Industry, Japan.

\section{References}

Becker, E. W.; Ehrfeld, W.; Hagmann, P.; Maner, A. \& Munchmeyer, D. (1986). Fabrication of microstructures with high aspect ratios and great structural heights by synchrotron 
radiation lithography, galvanoforming, and plastic moulding, Microelectron. Eng., Vol. 4, No. 1, 35-56, ISSN: 0167-9317

Ando, A.; Amano, S.; Hashimoto, S.; Kinoshita, H.; Miyamoto, S.; Mochizuki, T.; Niibe, M.; Shoji, Y.; Terasawa, M.; Watanabe, T. \& Kumagai, N. (1998). Isochronous storage ring of the New SUBARU project, I Synchrotron Rad., Vol. 5, Part 3, 342-344, ISSN: 0909-0495

Mekaru, H.; Utsumi, Y. \& Hattori, T. (2001). Beam line BL11 for LIGA process at the NewSUBARU, Nucl. Instrum. Methods A, Vol. 467-468, Part 1, 741-744, ISSN: 0168-9002

Mekaru, H.; Utsumi, Y. \& Hattori, T. (2002). Quasi-3D microstructure fabrication technique utilizing hard X-ray lithography of synchrotron radiation, Microsyst. Technol., Vol. 9, No. 1-2, 36-40, ISSN: 1432-1858

Mochizuki, H.; Mekaru, H.; Kusumi, S.; Sato, N.; Yamashita, M.; Shimada, O. \& Hattori, T. (2007). Design of solenoidal electromagnetic microactuator utilizing 3D X-ray lithography and metallization, Microsyst. Technol., Vol. 13, No. 5-6, 547-550, ISSN: 1432-1858

Matsumoto, Y.; Setomoto, M.; Noda, D. \& Hattori, T. (2008). Cylindrical coil created with 3D X-ray lithography and metallization for electromagnetic actuators, Microsyst. Technol., Vol. 14, No. 9-11, 1373-1379, ISSN: 1432-1858

Setomoto, M.; Matsumoto, Y.; Yamashita, S; Noda, D. \& Hattori, T. (2008). Fabrication of spiral micro coil lines for electromagnetic actuator, el Adv. Mech. Des. Syst. Manuf., Vol. 2, No. 2, 238-245, ISSN: 1881-3054

Noda, D.; Matsumoto, Y.; Setomoto, M. \& Hattori, T. (2007). Fabrication of coil lines with high aspect ratio for electromagnetic actuators, Proceedings of the 2007 IEEE International Symposium on Micro-Nano Mechatronics and Human Science, pp. 436-441, ISBN: 978-1-4244-1858-9, Nagoya University, November 2007, Nagoya, Japan

Noda, D.; Setomoto, M. \& Hattori, T. (2008a). Fabrication of microcoil with narrow and high aspect ratio lines for electromagnetic actuators, Proceedings of the 2008 IEEE International Symposium on Micro-Nano Mechatronics and Human Science, pp. 219-224, ISBN: 978-1-4244-2919-6, Nagoya University, November 2008, Nagoya, Japan

Yamashita, S; Matsumoto, Y.; Idei, K.; Okuda, K. Noda, D. \& Hattori, T. (2006). Fabrication of a cylindrical microcoil line with high aspect ratio for electromagnetic actuators, Proceedings of the 2006 IEEE International Symposium on Micro-Nano Mechatronics and Human Science, pp. 497-502, ISBN: 1-4244-0718-4, Nagoya University, November 2006, Nagoya, Japan

Noda, D.; Yamashita, S; Matsumoto, Y.; Setomoto, M. \& Hattori, T. (2008b). Fabrication of high aspect ratio microcoil using dipping method, I Adv. Mech. Des. Syst. Manuf., Vol. 2, No. 2, 174-179, ISSN: 1881-3054

Noda, D.; Matsumoto, Y.; Setomoto, M. \& Hattori, T. (2008c). Fabrication of microcoils using X-ray lithography and metallization, IEEJTransactions on Sensors and Micromachines, Vol. 128, No. 5, 181-185, ISSN: 1341-8939

Mekaru, H.; Kusumi, S.; Sato, N.; Yamashita, M.; Shimada, O. \& Hattori, T. (2004). Fabrication of mold master for spiral microcoil utilizing X-ray lithography, e $\mathrm{en}$. $\mathrm{C}$ Appl. Phys., Vol. 43, No. 6B, 4036-4040, ISSN: 1347-4065

Mekaru, H.; Kusumi, S.; Sato, N.; Shimizu, M.; Yamashita, M.; Shimada, O. \& Hattori, T. (2005). Development of three dimensional LIGA process to fabricate spiral microcoil, . fpn. el Appl. Phys., Vol. 44, No. 7B, 5749-5754, ISSN: 1347-4065

Mekaru, H.; Kusumi, S.; Sato, N.; Shimizu, M.; Yamashita, M.; Shimada, O. \& Hattori, T. (2007). Fabrication of a spiral microcoil using 3D-LIGA process, Microsyst. Technol., Vol. 13, No. 3-4, 393-402, ISSN: 1432-1858 


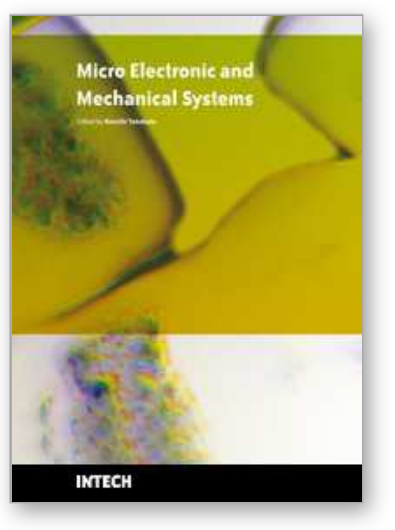

\author{
Micro Electronic and Mechanical Systems \\ Edited by Kenichi Takahata
}

ISBN 978-953-307-027-8

Hard cover, 386 pages

Publisher InTech

Published online 01, December, 2009

Published in print edition December, 2009

This book discusses key aspects of MEMS technology areas, organized in twenty-seven chapters that present the latest research developments in micro electronic and mechanical systems. The book addresses a wide range of fundamental and practical issues related to MEMS, advanced metal-oxide-semiconductor (MOS) and complementary MOS (CMOS) devices, SoC technology, integrated circuit testing and verification, and other important topics in the field. Several chapters cover state-of-the-art microfabrication techniques and materials as enabling technologies for the microsystems. Reliability issues concerning both electronic and mechanical aspects of these devices and systems are also addressed in various chapters.

\title{
How to reference
}

In order to correctly reference this scholarly work, feel free to copy and paste the following:

Daiji Noda, Masaru Setomoto and Tadashi Hattori (2009). Fabrication of High Aspect Ratio Microcoils for Electromagnetic Actuators, Micro Electronic and Mechanical Systems, Kenichi Takahata (Ed.), ISBN: 978-953307-027-8, InTech, Available from: http://www.intechopen.com/books/micro-electronic-and-mechanicalsystems/fabrication-of-high-aspect-ratio-microcoils-for-electromagnetic-actuators

\section{INTECH}

open science | open minds

\section{InTech Europe}

University Campus STeP Ri Slavka Krautzeka 83/A 51000 Rijeka, Croatia Phone: +385 (51) 770447

Fax: +385 (51) 686166 www.intechopen.com

\section{InTech China}

Unit 405, Office Block, Hotel Equatorial Shanghai No.65, Yan An Road (West), Shanghai, 200040, China 中国上海市延安西路65号上海国际贵都大饭店办公楼 405 单元 Phone: +86-21-62489820

Fax: $+86-21-62489821$ 
(C) 2009 The Author(s). Licensee IntechOpen. This chapter is distributed under the terms of the Creative Commons Attribution-NonCommercialShareAlike-3.0 License, which permits use, distribution and reproduction for non-commercial purposes, provided the original is properly cited and derivative works building on this content are distributed under the same license. 